\title{
OS NOVOS CONSTITUCIONALISMOS
}

Larissa Coelho ${ }^{1}$

Recebido em: 28/05/2019

Aceito em: 19/07/2019

larissacoelho1@gmail.com
"[...] se o nível de complexidade da sociedade modifica-se, a semântica orientadora do vivenciar e agir precisa adequar-se a ele, porque, senão, ela perde a conexão com a realidade"

Niklas Luhmann

Por ocasião do III Seminário Internacional Hispano-Luso-Brasileiro sobre Direitos Fundamentais e Políticas Públicas, ocorrido entre os dias 19 a 23 de março de 2018, promovido pelas Universidade de Santa Cruz do Sul (UNISC), Universidad de Coruña e pelo Centro de Estudos em Direito da União Europeia da Universidade do Minho (CEDU), tivemos a oportunidade de expor as complexas questões que se encontram em investigação no âmbito dos estudos doutorais em desenvolvimento na Universidade do Minho, que tem como tema central a teoria da constituição e a identificação de uma possível transformação do constitucionalismo, o que leva inclusive a doutrina a afirmar que encontramo-nos diante de um processo de mutação constitucional.

Deste modo, para compreender esta mutação, a questão que direciona o estudo corresponde ao interrogativo sobre qual a teoria da constituição se adequada à nossa realidade. Contudo, para que possamos responder à questão é necessário de antemão verificarmos em que consiste o nosso constitucionalismo atual, ou seja, como se desenha a sua teoria, uma vez que como afirma Gomes Canotilho em seu manual Direito Constitucional e Teoria da Constituição, não existe hoje "[...] uma situação clássica em sede da teoria da Constituição", entendendo-se por "[...] situação clássica aquela em que se verifica o acordo duradouro em termos de categorias teóricas, aparelhos conceituais e métodos de conhecimento". Fundamentando, de acordo com a visão do citado autor, no fato de que nos encontramos em verdade diante de uma "[...] divergência profunda quer quanto aos problemas constitucionais da contemporaneidade quer quanto às respostas dadas a esses problemas [...]"2.

Se vertermos a nossa análise sob o processo evolutivo do constitucionalismo, percebemos que este nunca foi estanque, no sentido de que apenas neste alvorecer do século XXI nos encontraríamos ante mudanças, pois que não se pode negar as contribuições que as "[...] grandes transformações sofridas pelo Estado e pela vida internacional ao longo do século XX [...]" nos proporcionaram ${ }^{3}$. Porém, no sentido clássico o constitucionalismo já correspondia a uma concepção plural visto que sua origem decorre de fatores advindos dos movimentos políticos revolucionários ocorridos na Inglaterra, França e Estados Unidos ${ }^{4}$, logo as primeiras impressões sobre o constitucionalismo advêm do constitucionalismo francês, do americano e do inglês.

\footnotetext{
${ }^{1}$ Universidade do Minho - UMINHO - Braga - Portugal

2 Cfr. J. J. Gomes Canotilho, Direito Constitucional e Teoria da Constituição, $7^{a}$ ed., Coimbra: Almedina, 2003, p. 1333 (negrito no original).

${ }^{3}$ Cfr. Jorge Miranda, "Democracia e Constituição para lá do Estado", RFDL, Lisboa, LI, n.ํㅗ 1/2, 2010, p. 33.

${ }^{4}$ Cfr. Carlos Blanco de Morais, Curso de Direito Constitucional: teoria da constituição em tempo de crise do Estado social, Tomo 2, vol. 2, Coimbra: Coimbra Editora, 2014, p. 308.
} 
Dentro deste parâmetro a tese nos leva a entender que do século XVIII herdaríamos então a concepção do constitucionalismo liberal, sucedido posteriormente pelo constitucionalismo social, cujas ideias associadas à internacionalização e promoção dos direitos humanos no período do póssegunda guerra, fundamentam o desenvolvimento do designado neoconstitucionalismo, de pretensão universalista ${ }^{5}$. Chegado ao século XXI e associando-se aos fatores da globalização desdobram-se as produções sobre o chamado direito constitucional internacional ou ainda constitucionalismo global que em virtude dos processos de integração regional dá origem há uma série de construções teóricas baseadas no diálogo ou entrelaçamento de soluções, para os designados problemas constitucionais hodiernos, não apenas em um nível local, mas numa componente global.

Uma vez que o artigo visa identificar o desenho atual do constitucionalismo, abdicaremos de uma análise do constitucionalismo histórico, pois que como argumenta Blanco de Morais, no tempo presente o constitucionalismo é "[...] servido por vários paradigmas [...]" que se assentam em "[...] fundamentos ideológicos, políticos, económicos e técnicos de matriz diversa" 6 , por isso a metodologia de pesquisa aplicada ao estudo corresponde ao método indutivo7. Desde modo, se por um lado merece nossa atenção o neoconstitucionalismo, por outro, é preciso verificar a relação entre a globalização e o constitucionalismo através das teorias que compõem a ideia de um constitucionalismo global ou internacional para que possamos então averiguar a possibilidade de uma resposta à questão inicialmente proposta.

Por isso, nosso recuo temporal leva-nos até o período do pós segunda guerra, uma vez que corresponde ao marco em que se intensifica o desenvolvimento doutrinário da proteção aos direitos humanos e fundamentais ${ }^{8}$, embora os catálogos de direitos e os problemas a esses associados já estivessem presentes na primeira fase do constitucionalismo, através dos textos americano (1776) e francês (1789), no entanto, será apenas com o pós-guerra que o seu processo de internacionalização se instaura, ampliando consequentemente uma conscientização por parte da sociedade para os problemas advindos destes, desencadeando o que Mark Tushnet, designa de globalização do direito constitucional ${ }^{9}$.

Neste contexto e através de uma lenta progressão, o direito internacional dos direitos humanos passa a ter primazia em detrimento do direito constitucional nacional, promovendo uma profunda transformação na teoria da constituição, visto que uma das consequências diretas deste fenômeno foi o contributo para uma redução significativa do conceito de soberania e posteriormente

\footnotetext{
${ }^{5}$ Cfr. Morais, Curso de Direito Constitucional... op. cit., 2014, p. 304.

${ }^{6}$ Cfr. Morais, Curso de Direito Constitucional... op. cit., 2014, p. 309.

7 Cfr. Miracy Barbosa de Sousa Gustin; Maria Tereza Fonseca Dias, (Re)pensando a pesquisa jurídica: teoria e prática, 3aㅡ ed. rev. e atual., Belo Horizonte: Del Rey, 2010, p. 22-23.

8 Cfr. Mark Tushnet, "The Inevitable Globalization of Constitutional Law", Harvard Public Law Working Paper No. 09-06, December 18, 2008, p. 1-2, [consult. 13.06.2018], disponível em: http://dx.doi.org/10.2139/ssrn.1317766.

9 Cfr. Tushnet, The Inevitable Globalization... op. cit., 2008. No mesmo sentido do pensamento de Tushnet, Chris Thornhill afirma que "[t]he post-1945 period saw an exponential rise in the force of international law, and most especially of that branch of international law focused on promoting human rights norms", cfr. Chris Thornhill, A Sociology of Transnational Constitutions, Cambridge: Cambridge University Press, 2016, p.70, [consult. 13.06.2018], disponível em: http://dx.doi.org/10.1017/CBO9781139833905.
} 
para a limitação da autonomia do Estado-Nação ${ }^{10}$, embora paralelamente tenha permitido a efetivação de uma ideologia jurídica com base em princípios fundamentais, que representou conforme explica Luís Roberto Barroso uma espécie de renascimento do direito constitucional ${ }^{11}$, florescendo neste contexto a doutrina do neoconstitucionalismo.

Embora o neoconstitucionalismo tenha como principais referências a constituição alemã (1949) e italiana (1947), sua aplicação enquanto método teórico dá-se nos países situados a sul da Europa (especialmente, Portugal e Espanha após os processos de redemocratização), África Austral e sobretudo na América Latina com destaque para o Brasil e a efetivação dos direitos sociais, com a Constituição Federal de 1988, que tem vindo a ser traduzido como o "fermento" para o ativismo judicial ${ }^{12}$.

No plano teórico as contribuições do neoconstitucionalismo vão no sentido do reconhecimento da força normativa da Constituição, a expansão da jurisdição constitucional e o desenvolvimento de uma nova dogmática para a interpretação constitucional ${ }^{13}$. A ideia jusfilosófica subjacente é o da constituição cidadã e por isso sua essência corresponde à carta de direitos fundamentais, que assume uma posição dirigente concretizadora da força normativa. Por esta razão a doutrina afirma que o neoconstitucionalismo cria "[...] uma narrativa constitucional centrada em torno de um papel heroico, utópico e transformador da Constituição em torno da valorização dos direitos sociais [...]"14, porém para conseguir seu intento a teoria aposta no reforço do papel dos tribunais, especialmente os vocacionados para o controle da constitucionalidade, atualizando e reafirmando o princípio da separação de poderes em que os tribunais passam a atuar não apenas como legislador negativo através das declarações de inconstitucionalidade mas também tornam-se legisladores positivos por via da concretização jurisprudencial de normas constitucionais. Para tanto, dá primazia a distinção entre regras e princípios, em que os segundos indicam o sentido interpretativo dos primeiros, passando as normas consagradoras de direitos fundamentais a ter eficácia direta. Por sua vez, alude a doutrina que uma constituição considerada principiologicamente aberta "[...] reclamaria uma sociedade aberta de intérpretes comprometidos com a realização dessas funções, com relevo para os tribunais ordinários os quais não poderiam ser amarrados ao método jurídico da interpretação defendido pelo positivismo", permitindo assim a criação de uma nova hermenêutica ${ }^{15}$.

Contudo, o neoconstitucionalismo distancia-se da tendência internacionalista, visto que não se depreende dos seus fundamentos o questionamento sobre a noção de Estado e seus elementos,

10 Cfr. Thornhill, A Sociology of Transnational... op. cit., 2006, 70 e Tushnet, The Inevitable Globalization... op. cit., 2008, p. 2-3. Essa desvinculação dos conceitos de constituição e Estado é defendida por Peter Häberle no argumento de que não seria o Estado o objeto da Constituição uma vez que a premissa desta é de base antropológica e assim deve se fundar na dignidade humana, logo nos cidadãos e seres humanos, cfr. Peter Häberle, El Estado Constitucional, tradução por Héctor FixFierro, México: Universidad Nacional Autónoma de México, 2003, p. 14.

${ }^{11}$ Cfr. Luís Roberto Barroso, "Neoconstitucionalismo e constitucionalização do Direito (O triunfo tardio do direito constitucional no Brasil)", Revista de Direito Administrativo, Rio de Janeiro, v. 240, abr. 2005, p. 3, [consult. 13.06.2018], disponível em: http://dx.doi.org/10.12660/rda.v240.2005.43618

12 Cfr. Morais, Curso de Direito Constitucional... op. cit., 2014, p. 304-368.

13 Cfr. Luís Roberto Barroso, Curso de Direito Constitucional Contemporâneo: os conceitos fundamentais e a construção do novo modelo, São Paulo: Saraiva, 2015, p. 520-521.

14 Cfr. Morais, Curso de Direito Constitucional... op. cit., 2014, p. 369.

15 Cfr. Morais, Curso de Direito Constitucional... op. cit., 2014, p. 369-370. 
tampouco busca soluções para as questões que passam a ser levantadas em decorrência dos processos de integração regional, bem como não apresenta argumentos sobre a influência dos fatores da globalização no direito. Por essa razão, com os desenvolvimentos políticos e econômicos ao longo da segunda metade do século $X X$ o neoconstitucionalismo passa a ter pouco impacto no continente europeu que em função do processo de construção da comunidade europeia, posterior União Europeia, e um entendimento amplo da globalização, ultrapassa a noção clássica de um constitucionalismo delimitado por fronteiras territoriais abrindo a discussão para as construções jurídicas transnacionais.

As primeiras manifestações do direito transnacional segundo a doutrina especialista dá-se com os tratados internacionais e o aparecimento de atores transnacionais, como os tribunais transnacionais, a exemplo do Tribunal Europeu de Direitos Humanos (TEDH) que passam a influenciar os quadrantes nacionais através da transposição e adoção de suas diretrizes interligando diferentes ordens jurídicas. Neste mesmo sentido, observa-se uma crescente influência das sentenças dos tribunais ou cortes constitucionais, difundidas tanto pela publicitação das sentenças em si, quanto por meio de obras acadêmicas, que criam uma espécie de incentivo para que os juízes constitucionais ponderem a adoção de soluções encontradas em ordenamentos jurídicas distintos ${ }^{16}$.

A doutrina também aponta como fator de influência para essa nova construção jurídica a interação entre o constitucionalismo e a globalização, devendo esta ser entendida não apenas na sua perspectiva economicista, mas como um processo de interconexão e interação entre pessoas e nações promovidas através do desenvolvimento dos transportes, comunicações, turismo, migrações, informações, avanços tecnológicos e científico ${ }^{17}$, nos colocando em face de um momento de transição, pois que como observam Zygmunt Bauman e Ulrich Beck, é a globalização a responsável pela expropriação ou corrosão dos fundamentos do Estado, fragmentação que ocorre em favor de diferentes grupos e organizações, traduzindo-se na possibilidade da criação de governos em vários $n^{n}$ veis $^{18}$, logo, presenciamos o fim da era dos Estados enquanto entidades isoladas e autónomas, em razão do surgimento de novos atores com capacidade para influenciar ou criar o direito. Neste contexto, identifica Francisco Paoli Bolio como correspondente às matérias que passam prioritariamente a ser tratadas sob uma lógica transnacional os direitos humanos, o comércio, a política de segurança, a proteção ambiental, a preservação da biodiversidade e o equilíbrio ecológico ${ }^{19}$.

${ }^{16}$ Cfr. Tushnet, The Inevitable Globalization... op. cit., 2008, p. 4-6.

17 Cfr. Francisco José Paoli Bolio, Constitucionalismo en el siglo XXI. A cién años de la aprobación de la Constitución de 1917, Ciudad de México: Senado de la República, Secretaría de Cultura, Instituto Nacional de Estudios Históricos de las Revoluciones de México, UNAM, Instituto de Investigaciones Jurídicas, 2016, p. 175-176.

18 Cfr. Zygmunt Bauman, Globalização: as consequências humanas, tradução por Marcus Penchel, Rio de Janeiro: Jorge Zahar Ed., 1999, p. 66-71; Ulrich Beck, O que é globalização? Equívocos do globalismo, respostas à globalização, tradução por André Carone, São Paulo: Paz e Terra, 1999 e Cristina Queiroz, Direito Constitucional Internacional, Coimbra: Coimbra Editora, 2011, p. 30-31.

${ }^{19}$ Cfr. Paoli Bolio, Constitucionalismo en el siglo XXI... op. cit, 2016, p. 176. O final da guerra fria marca cronologicamente, segundo a doutrina o período no qual as ideias transnacionais passam a se intensificar uma vez que é a partir de então que o mundo deixa de se ver dividido políticoideologicamente entre capitalismo-comunismo, cedendo lugar ao avanço de grandes mercados econômicos, com destaque para o NAFTA (Tratado Norte-Americano de Livre Comércio, formado 
Diante deste contexto de transformação o Estado vem perdendo a "[...] governança no contexto do governo nacional aos níveis locais, regional, transnacional e global" ${ }^{20}$, implicando na compreensão de que o constitucionalismo se emancipa do Estado "[...] não precisamente porque surgiu uma multidão de novas Constituições, mas sim tendo em vista que outras ordens jurídicas estão envolvidas diretamente na solução dos problemas constitucionais básicos [...]"21. Como consequência, ao observar este fenômeno a doutrina jurídica inquire da necessidade de uma "[...] revisitação e re-interpretação dos conceitos jusconstitucionais [...]"22, indo ao encontro às propostas desenhadas pelo constitucionalismo global ou ainda direito constitucional internacional, nos colocando na presença dos "novos constitucionalismos"23, conjuntura na qual se desenvolve as seguintes teorias: o transconstitucionalismo, o constitucionalismo societário, o constitucionalismo cooperativo, o constitucionalismo multinível e a interconstitucionalidade ${ }^{24}$.

A teoria do transconstitucionalismo é desenvolvida por Marcelo Neves que rejeita a ideia de que uma única ordem jurídica possua a solução ideal para os problemas constitucionais. Assim, as ordens estatais, internacionais, supranacionais, transnacionais e locais que atualmente existem são incapazes de oferecer respostas adequadas para os problemas normativos contemporâneos e por isso a solução encontra-se no entrelaçamento entre as normas já existentes, possibilitando a criação de pontes de transição entre ordens jurídicas distintas ${ }^{25}$.

A teoria do constitucionalismo societário advoga que estamos diante de uma "nova questão constitucional", que surge a partir das energias sociais construídas pela economia, ciência, tecnologia, medicina e comunicação social, cujos efeitos são transnacionais, por isso, para o seu autor, Gunther Teubner, em razão da globalização, estaríamos ante uma constituição civil global, sem estado mundial composta por constituições civis parciais, articulando diversos subsistemas autônomos. Logo, esta teoria assenta-se na ideia de que se transferiria para diversas instituições certas políticas dos Estados, introduzindo uma espécie de governança privada, ao passo que as constituições civis parciais por serem autónomas deixam de necessitar de intervenção política em contextos de crise, uma vez que o poder estaria partilhado, processando-se àquilo que o autor designa por constitucionalização da sociedade ${ }^{26}$.

O constitucionalismo cooperativo é a tese apresentada por Peter Häberle na qual a Constituição é entendida como uma via aberta para o futuro, deste modo, a resposta aos problemas constitucionais deve partir da interação entre o direito constitucional e o direito internacional que

pelos Estados Unidos, Canadá e México), União Europeia e os designados Tigres Asiáticos (expressão que identifica segundo os economistas o desenvolvimento económico-financeiro a partir de 1970 de Singapura, Hong Kong, Coreia do Sul e Taiwan).

${ }^{20}$ Cfr. Queiroz, Direito Constitucional Internacional... op. cit., 2011, p. 7.

${ }^{21}$ Cfr. Marcelo Neves, Transconstitucionalismo, São Paulo: Editora WMF Martins Fontes, 2009, p. $\mathrm{XXI}$.

22 Cfr. Queiroz, Direito Constitucional Internacional... op. cit., 2011, p. 8.

${ }^{23}$ Cfr. Canotilho, Direito Constitucional... op. cit., 2003, p. 17.

${ }^{24}$ Mais sobre as teorias indicadas ver Larissa A. Coelho, "O ensino do direito constitucional na era da globalização", in Desafios do ensino jurídico no século XXI, orgs. Fabrício Veiga Costa; Ivan Dias da Motta; Sérgio Henrique Zandona Freitas, Maringá: IDDM, 2018, p. 361 - 387.

${ }^{25}$ Cfr. Neves, Transconstitucionalismo... op. cit., 2009, p. 119-131.

${ }^{26}$ Cfr. Gunther Teubner, "Reflexões sobre a constitucionalização do sistema de poder mundial", Revista Brasileira de Sociologia do Direito, Recife, vol. 5, n.. 1, jan/abr., 2018, p. 5 - 9, [consult, 13.06.2018], disponível em http://dx.doi.org/10.21910/rbsd.v5n1.2018.231. 
passam a estar unidos por um elo de cooperação, transformando-se e influenciando-se mutuamente, pois que o direito constitucional se abre às mudanças e aos desafios apresentados pelo direito internacional27.

Por sua vez, o constitucionalismo multinível, observado por Ingolf Pernice analisa o desenvolvimento do constitucionalismo a partir do prisma da integração europeia e do Tratado da União Europeia, no qual se mantém em vigor as constituições dos Estados-Membros que passam a conviver com uma constituição supranacional. Deste modo, esta relação se fundamenta no compartilhamento de poderes entre os Estados-Membros e as instituições europeias, nas palavras do autor "[t]he concept of multilevel constitutionalism was developed to explain [...] this system as a result of a process of establishing progressively a supranational level of public authority based on the national constitutions and binding them together to one composed constitutional system [...]"28.

Por fim, a teoria da interconstitucionalidade, desenvolvida por autores lusófonos, explica que a resposta aos problemas constitucionais encontra-se na aplicação do diálogo constitucional. Observando também a realidade europeia, esta teoria orienta-se pela fusão do patrimônio jurídico comum, que se dá através da "[...] concorrência, convergência, justaposição e conflito de várias constituições e de vários poderes constituintes no mesmo espaço político" ${ }^{29}$, fundamentando o pluralismo constitucional. Deste modo, as Constituições dantes exclusivamente nacionais passam também a integrar-se, a entrar em diálogo com os textos constitucionais de outros Estados-Membros e com os textos constitucionais supranacionais ${ }^{30}$, o que nos coloca diante da ideia síntese de que "[...] as constituições dos Estados 'supranacionalizaram-se' ou 'internacionalizaram-se "'31.

Face ao exposto, verificamos que é sobretudo no período do pós-segunda guerra que novas ideias passam a inundar a teoria da constituição, especialmente estimulados pela internacionalização e promoção dos direitos humanos e fundamentais. Assim dois caminhos são apresentados, por um lado, temos um constitucionalismo fundado nas ideias nascidas de uma pretensão universalista, que tem por foco os princípios fundamentais e a sua afirmação através da aplicabilidade direta e da demarcação de um posicionamento ativo dos tribunais, consubstanciando a teoria do neoconstitucionalismo. Por outro lado, em função da internacionalização e dos fenômenos da globalização que passam a se intensificar, o próprio direito constitucional se globaliza e torna-se território para a criação e desenvolvimento das ideias relacionadas a um constitucionalismo supranacional, apresentando a doutrina como aportes teóricos as teorias do transconstitucionalismo,

${ }^{27}$ Cfr. Peter Häberle, Estado constitucional cooperativo, Rio de Janeiro: Renovar, 2007, p. 10.

${ }^{28}$ Cfr. Ingolf Pernice, Multilevel constitutionalism in the European Union, WHI-Paper 5/02, Berlin: Walter Hallstein-Institut, Humboldt-Universität Berlin, 2001, p. 4, [consult. 13.06.2018], disponível em http://www.whi-berlin.de/documents/whi-paper0502.pdf.

${ }^{29}$ Cfr. J. J. Gomes Canotilho, "Brancosos" e interconstitucionalidade: itinerários dos discursos sobre a historicidade constitucional, Coimbra: Almedina, 2008, p. 266 e Canotilho, Direito Constitucional... op. cit., 2003, p. 1425.

${ }^{30}$ Cfr. Larissa A. Coelho, "O ideal constitucional: das origens à teoria da interconstitucionalidade", in UNIO/CONPEDI E-book 2017. Interconstitucionalidade: democracia e cidadania de direitos na sociedade mundial - atualização e perspectivas, vol. II, coord. Alessandra Silveira, Braga: Centro de Estudos em Direito da União Europeia, 2018, p. 212, [consult. 13.06.2018], disponível em http://www.unio.cedu.direito.uminho.pt/Uploads/Ebook\%202016/UNIO-CONPEDI\%20Ebook\%202017\%20Vol.\%202.pdf.

${ }^{31}$ Cfr. J. J. Gomes Canotilho, "O Estado no Direito Constitucional Internacional", Revista da História das Ideias, Coimbra, vol, 26, 2005, p. 343. 
constitucionalismo societário, constitucionalismo cooperativo, constitucionalismo multinível e a interconstitucionalidade, ou seja, verificamos uma "[...] abertura do constitucionalismo para além do Estado"32.

Neste sentido, o atual desenho do constitucionalismo em verdade encontra-se arquitetado em vários níveis, o que nos permite afirmar que vivenciamos um constitucionalismo que se desenvolve em vários níveis, pois que as diversas teorias em análise procuram responder aos problemas constitucionais mas com base em perspectivas diversas, assim, enquanto 0 neoconstituionalismo preocupa-se com a afirmação e concretização das normas constitucionais, sendo o seu pilar o Estado, não estando em causa as questões levantadas pelo diálogo entre ordenamentos jurídicos diversos, ao passo que, as teorias que compõem o chamado constitucionalismo global, em seu conjunto, embora partam sob pontos de análise distintos, preocupam-se em dar uma resposta em rede aos atuais problemas do constitucionalismo, ou seja, interconectando diversos ordenamentos. Logo, embora se debrucem sob um mesmo objeto, as respostas vão sendo construídas e desenvolvidas em vários níveis, o que nos coloca de fato diante de constitucionalismos, no plural, demonstrando assim um processo evolutivo que permanece sempre em atualização, e por isso finalizamos com o pensamento de Karl von Stein, que em princípios do século XIX já dizia que a constituição enquanto "resultado de ações humanas" deve ser compreendida como um "degrau que o gênero humano precisa vencer, mas um degrau que ele em breve deverá transpor e no qual não poderá ficar eternamente"33.

\section{REFERÊNCIAS}

BARROSO, Luís Roberto, Curso de direito constitucional contemporâneo: os conceitos fundamentais e a construção do novo modelo, 5ª ed, São Paulo: Saraiva, 2015.

BARROSO, Luís Roberto, "Neoconstitucionalismo e constitucionalização do Direito (O triunfo tardio do direito constitucional no Brasil)", Revista de Direito Administrativo, Rio de Janeiro, v. 240, p. 1-42, abr. 2005, [consult. 13.06.2018], disponível em: http://dx.doi.org/10.12660/rda.v240.2005.43618.

BAUMAN, Zygmunt, Globalização: as consequências humanas, tradução por Marcus Penchel, Rio de Janeiro: Jorge Zahar Ed., 1999.

BECK, Ulrich, O que é globalização? Equívocos do globalismo, respostas à globalização, tradução por André Carone, São Paulo: Paz e Terra, 1999.

COELHO, Larissa A., "O ideal constitucional: das origens à teoria da interconstitucionalidade", in UNIO/CONPEDI E-book 2017. Interconstitucionalidade: democracia e cidadania de direitos na sociedade mundial - atualização e perspectivas, vol. II, coord. Alessandra Silveira, Braga: Centro de Estudos em Direito da União Europeia, 2018, [consult. 13.06.2018], disponível em: http://www.unio.cedu.direito.uminho.pt/Uploads/Ebook\%202016/UNIO-CONPEDI\%20Ebook\%202017\%20Vol.\%202.pdf

${ }^{32}$ Cfr. Neves, Transconstitucionalismo...op. cit., 2009, p. 120.

${ }^{33}$ Karl Fr. von Stein zum Altenstein, 1807, apud Dieter Grimm, "Constituição, lei fundamental (leis fundamentais) da llustração até os dias atuais", in Constituição: história do conceito da antiguidade aos nossos dias, org. Heinz Mohnhaupt e Dieter Grimm, Belo Horizonte: Livraria Tempus, 2012, p. 170. 
COELHO, Larissa A. "O ensino do direito constitucional na era da globalização", in Desafios do ensino jurídico no século XXI, orgs. Fabrício Veiga Costa; Ivan Dias da Motta; Sérgio Henrique Zandona Freitas, Maringá: IDDM, 2018, p. 361 - 387.

CANOTILHO, J. J. Gomes, "Brancosos" e interconstitucionalidade: itinerários dos discursos sobre a historicidade constitucional, Coimbra: Almedina, 2008.

CANOTILHO, J. J. Gomes, Direito Constitucional e Teoria da Constituição, $7^{a}$ ed., Coimbra: Almedina, 2003.

CANOTILHO, J. J. Gomes, "O Estado no Direito Constitucional Internacional", Revista da História das Ideias, Coimbra, vol, 26, p. 343-352, 2005.

GRIMM, Dieter, "Constituição, lei fundamental (leis fundamentais) da llustração até os dias atuais", in Constituição: história do conceito da antiguidade aos nossos dias, org. Heinz Mohnhaupt e Dieter Grimm, Belo Horizonte: Livraria Tempus, 2012.

GUSTIN, Miracy Barbosa de Sousa e Maria Tereza Fonseca Dias, (Re)pensando a pesquisa jurídica: teoria e prática, $3^{\text {a }}$ ed. rev. e atual., Belo Horizonte: Del Rey, 2010.

HÄBERLE, Peter, El Estado Constitucional, tradução por Héctor Fix-Fierro, México: Universidad Nacional Autónoma de México, 2003.

HÄBERLE, Peter, Estado constitucional cooperativo, Rio de Janeiro: Renovar, 2007.

LUHMANN, Niklas, "Gesellschaftliche Struktur und semantische Tradition", in Gesellschaftsstruktur und Semantik: Studien zur Wissenssoziologie der modernen Gesellschaft, v. 1, org. Niklas Luhmann, Frankfurt: Suhrkamp, 1980.

MIRANDA, Jorge, “Democracia e Constituição para lá do Estado”, RFDL, Lisboa, LI, n. ㅇs 1/2, 2010.

MORAIS, Carlos Blanco de, Curso de Direito Constitucional: teoria da constituição em tempo de crise do Estado social, Tomo 2, vol. 2, Coimbra: Coimbra Editora, 2014.

NEVES, Marcelo, Transconstitucionalismo, São Paulo: Editora WMF Martins Fontes, 2009.

PAOLI BOLIO, Francisco José, Constitucionalismo en el siglo XXI. A cién años de la aprobación de la Constitución de 1917, Ciudad de México: Senado de la República, Secretaría de Cultura, Instituto Nacional de Estudios Históricos de las Revoluciones de México, UNAM, Instituto de Investigaciones Jurídicas, 2016.

PERNICE, Ingolf, Multilevel constitutionalism in the European Union, WHI-Paper 5/02, Berlin: Walter Hallstein-Institut, Humboldt-Universität Berlin, 2001, [consult. 13.06.2018], disponível em: http://www.whi-berlin.de/documents/whi-paper0502.pdf.

PIRES, Francisco Lucas, Introdução ao direito constitucional europeu: seu sentido, problemas e limites, Coimbra: Almedina, 1997.

QUEIROZ, Cristina, Direito Constitucional Internacional, Coimbra: Coimbra Editora, 2011.

SILVEIRA, Alessandra, "Do dirigismo constitucional à interconstitucionalidade 'com cheirinho de alecrim ' (a propósito da projeção externa da CRP de 1976 na CF de 1988) in Nos 40 anos da Constituição, ed. Jorge Miranda, Lisboa: AAFDL Editora, 2017.

SILVEIRA, Alessandra, "International Constitutional Court e integração (constitucional) europeia", International Studies on Law and Education, 24, p. 71-76, set. - dez., 2016, [consult. 13.06.2018], disponível em: http://www.hottopos.com/isle24/71-76Silveira.pdf.

TEUBNER, Gunther, "Globale Zivilverfassungen: Alternativen zur staatszentrierten", Verfassungstheorie. Zeitschrift für ausländisches öffentliches Recht und Völkerrecht (ZaöRV), vol. 63, 
p. 1-28, 2003, [consult. 13.06.2018], disponível em: http://www.zaoerv.de/63_2003/63_2003_1_a_1_28.pdf.

TEUBNER, Gunther, "Reflexões sobre a constitucionalização do sistema de poder mundial", Revista Brasileira de Sociologia do Direito, Recife, vol. 5, n. 1, p. 4-23, jan/abr., 2018, [consult. 13.06.2018], disponível em: http://dx.doi.org/10.21910/rbsd.v5n1.2018.231.

THORNHILL, Chris, A Sociology of Transnational Constitutions, Cambridge: Cambridge University Press, 2016, [consult. 13.06.2018], disponível em: http://dx.doi.org/10.1017/CBO9781139833905.

TUSHNET, Mark, "The Inevitable Globalization of Constitutional Law", Harvard Public Law Working Paper No. 09-06, p. 1-22, December 18, 2008, [consult. 13.06.2018], disponível em: http://dx.doi.org/10.2139/ssrn.1317766.

\section{COMO CITAR ESSE DOCUMENTO:}

COELHO, Larissa. OS NOVOS CONSTITUCIONALISMOS. Revista do Direito, Santa Cruz do Sul, v. 1, n. 57, jul. 2019. ISSN 1982-9957. Disponível em: <https://online.unisc.br/seer/index.php/direito/article/view/13571>. Acesso em: doi:https://doi.org/10.17058/rdunisc.v1i57.13571. 